\title{
Numerical study on the effect of shaft position on natural smoke exhaust in tunnels with one closed portal
}

\author{
GENG Pengqiang ${ }^{l}$, WANG Zihao $^{2}$, WENG Miaocheng ${ }^{1,3, *}$, LIU Fang $^{1,3, *}$ \\ ${ }^{1}$ School of Civil Engineering, Chongqing University, Chongqing 400045, China; \\ ${ }^{2}$ College of Environment and Ecology, Chongqing University, Chongqing, 400045, China; \\ ${ }^{3}$ Key Laboratory of The Three Gorges Reservoir Region's Eco-Environment, Ministry of Education, Chongqing 400045, China;
}

\begin{abstract}
This paper uses Fire Dynamics Simulator (FDS) to study the effect of the longitudinal distance from the shaft to the fire source on the natural smoke exhaust of the tunnel fire with one closed portal, and analyzes the temperature distribution of the smoke and the shaft's smoke exhaust efficiency. The results show that when the shaft is located downstream of the fire source $\left(D_{s}<0\right)$, with the increase of the distance from the shaft to the fire source, the smoke exhaust efficiency decreases first and then stabilizes at a fixed value. At this time, the ceiling temperature attenuation's coefficient at upstream of the fire source is only related to the heat release rate of the fire source (HRR). When the shaft is located upstream of the fire source $\left(D_{s}>0\right)$, the smoke exhaust efficiency increases slightly with the increase of the distance from the shaft to the fire source, but the overall value is relatively small. When HRR is fixed, the shaft located downstream of the fire source has a higher smoke exhaust efficiency. As the distance between the shaft and the fire source increases, the plug phenomenon decreases.
\end{abstract}

\section{Intruduction}

Recently, mountainous cities (such as Hong Kong and Chongqing, etc.) often encounter limited space on the ground in urban subway planning. One suggestion is to use tunnel-type train maintenance library. Compared with traditional train maintenance library, it includes multiple branch tunnels, each with a blocking end. Compared with traditional tunnels, it has a shorter length (less than 200m).

Once the tunnel catches fire, the high-temperature smoke generated by the fire will reduce the visibility of the tunnel and increase the difficulty of evacuation. Therefore, a well-designed ventilation system mainly includes mechanical ventilation (longitudinal ventilation ${ }^{[1]}$, transverse ventilation ${ }^{[2]}$, semi-transverse ventilation ${ }^{[3]}$ ) system and natural ventilation system, which can ensure the safety of trapped persons. The mechanical ventilation system is less affected by the external environment and has high stability. However, the mechanical ventilation system requires strict daily maintenance. When a transverse or semi-transverse ventilation system is used, a separate air duct is required, which will reduce the clear height of the tunnel. The use of longitudinal ventilation requires good ventilation conditions at both ends of the tunnel. On the other hand, natural ventilation systems include shafts ${ }^{[4]}$, ceiling openings ${ }^{[5]}$ and other forms. The structure is simple and the cost is low, which is particularly suitable for short tunnels.

Designing proper natural ventilation shaft parameters can improve smoke exhaust performance. Some scholars have studied the effects of the shaft cross-sectional area, shaft aspect ratio, shaft height, number and location of shafts on smoke emission performance. Fan et al ${ }^{[6]}$ studied the influence of different fire source positions between two shafts on the natural ventilation performance of the tunnel. Takeuchi et al ${ }^{[7]}$ studied the natural ventilation performance of a road tunnel with 6 shafts through small-scale experiments. Guo et al ${ }^{[8]}$ studied the smoke flow characteristics of multiple vertical shafts with large cross-sections. They observed that when the height of the shaft reaches a certain value, the fresh air under the smoke layer will be directly discharged through the shaft. This phenomenon is called plug. Xie et al ${ }^{[9]}$ found that as the cross-sectional area of the shaft and the shaft aspect ratio increase, the plug phenomenon becomes more serious. Ji et al ${ }^{[10]}$ observed that the critical shaft height can effectively avoid boundary layer separation and plug phenomenon, and proposed the Richardson number Ri as a criterion, and suggested that the critical value of $\mathrm{Ri}$ can be roughly determined as 1.4 .

Smoke exhaust efficiency is an important indicator of the ventilation system. It refers to the ratio of the heat carried by the smoke exhausted through the exhaust vent to the heat carried by the smoke at upstream of the exhaust vent. Wang et al ${ }^{[11]}$ proposed a method for calculating the mass flow rate of the shaft under the conditions of plug phenomenon and no plug phenomenon. Yuan et al [12] used small-scale experiments combined with theoretical analysis to study the plug phenomenon, and proposed a prediction model to predict the distribution of the tunnel ceiling's smoke temperature and the shafts' smoke exhaust efficiency, which concludes shaft size and shaft

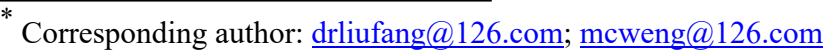


spacing. He et al ${ }^{[13]}$ studied the influence of shaft height and fire source heat release rate (HRR) on the smoke exhaust efficiency of the shaft in the 1:10 tunnel model, and found that as the shaft height increases, the smoke exhaust efficiency of the shaft first decreases and then increase. At the same time, some researchers seek to improve the structure of the shaft to improve the efficiency of smoke extraction. Cong et al ${ }^{[14]}$ studied the process of exhausting smoke through a board-coupled shaft during a tunnel fire. Ji et al ${ }^{[15]}$ proposed the use of oblique angles in tunnel shaft connections to avoid boundary layer separation and plug, which can improve smoke exhaust efficiency.

Previous studies on the efficiency of shaft's smoke extraction were mostly aimed at tunnels with open ends. In this article, a series of simulations about the 1:10 tunnel models with one closed portal were made to study the influence of the shaft position on tunnel ceiling's smoke temperature distribution and shaft's smoke exhaust efficiency. A prediction model for the ceiling's smoke temperature at upstream of the fire source is established. The conclusion can provide a reference for the design of the natural smoke exhaust system of a blocked tunnel at one end.

\section{Numerical simulation}

FDS is the CFD open source software developed by the Building Fire Research Laboratory of the American National Standards Institute to simulate fluid movement in fires. It can well simulate low Mach numbers (less than 0.3 ) and the heat transmission of fluids driven by thermal. So it is often used to study tunnel fires. This article uses FDS 6.7.0 for follow-up research.

\subsection{Set-up of simulations}

The model tunnel is built according to the ratio of 1:10, and its size is $11 \mathrm{~m}($ length $) \times 1 \mathrm{~m}($ width $) \times 0.5 \mathrm{~m}$ (height). The section size of the shaft is $0.1 \mathrm{~m} \times 0.1 \mathrm{~m}$ and its height is $1 \mathrm{~m}$. According to Wang ${ }^{[16]}$, when the model has a certain extension domain, the simulation results will be more accurate. Therefore, an extensive domain of $1 \mathrm{~m}$ $($ length $) \times 2 \mathrm{~m}$ (width) $\times 1 \mathrm{~m}$ (height) was added at the open end of the model and an extensive domain of $0.2 \mathrm{~m} \times 0.2 \mathrm{~m}$ $\times 0.2 \mathrm{~m}$ was added at the open end of the shaft. The model tunnel takes the blocked end as the longitudinal coordinate origin $(X=0 \mathrm{~m})$, and the coordinate of the open end is $X=11 \mathrm{~m}$. Six positions of shafts are studied ( $X_{s}=1 \mathrm{~m}$, $3 \mathrm{~m}, 5 \mathrm{~m}, 6 \mathrm{~m}, 8 \mathrm{~m}$, and $10 \mathrm{~m}) . \mathrm{X}_{\mathrm{s}}$ is the coordinate of the center of the shaft cross section. The schematic diagram of the model is shown in Figure $1\left(X_{s}=1 \mathrm{~m}\right)$.

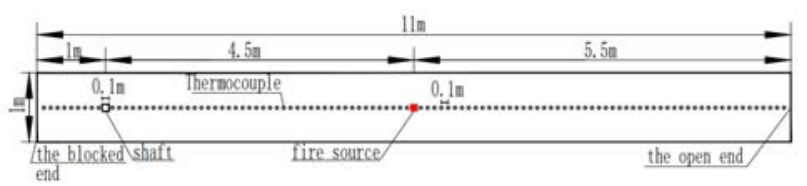

(a) Top view

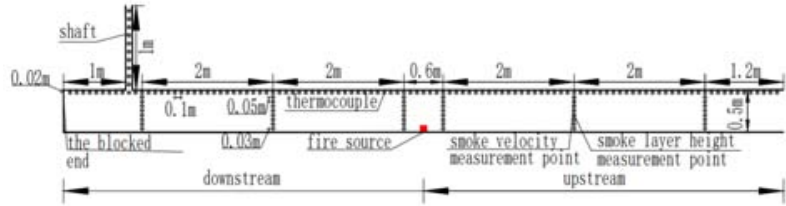

(b) Side view

Fig. 1. Schematic diagram of FDS model

In order to simulate the ethanol pool fire in the actual small-scale experiment, the design fire source heat release rate (HRR) is $3.57 \mathrm{KW}, 5.08 \mathrm{KW}, 8.51 \mathrm{KW}$ and 15.16 $\mathrm{KW}$ (corresponding to the HRR in the full-scale tunnel is 1.13MW to $4.79 \mathrm{MW})$. The corresponding fire source size is $0.1 \times 0.1 \mathrm{~m}^{2}, 0.12 \times 0.12 \mathrm{~m}^{2}, 0.15 \times 0.15 \mathrm{~m}^{2}, 0.2 \times 0.2 \mathrm{~m}^{2}$. The fire source is located at the center of the tunnel. The fire source center is $5.5 \mathrm{~m}$ away from both the blocked end and the open end of the tunnel, which coordinate $X_{f}=5.5 \mathrm{~m}$.

For the purpose of studying the influence of shaft position on tunnel smoke exhaust, the distance between shaft and fire source is defined as $\mathrm{D}_{\mathrm{s}}$ :

$$
D_{s}=X_{s}-X_{f}
$$

$D_{s}$ ranges from $-4.5 \mathrm{~m}$ to $4.5 \mathrm{~m}$. The specific simulation settings are shown in Table 1.

Table 1. Numerical simulation scheme

\begin{tabular}{|c|c|c|}
\hline $\begin{array}{c}\text { Case } \\
\text { Grouping }\end{array}$ & HRR/KW & $\mathbf{D}_{\mathbf{s}} / \mathbf{m}$ \\
\hline $1-4$ & $\begin{array}{c}3.57,5.08, \\
8.51,15.16\end{array}$ & $\begin{array}{c}\text { Without } \\
\text { Shaft }\end{array}$ \\
\hline $5-10$ & 3.57 & $\begin{array}{c}-4.5,-2.5,-0.5 \\
0.5,2.5,4.5\end{array}$ \\
\hline $11-16$ & 5.08 & $\begin{array}{c}-4.5,-2.5,-0.5 \\
0.5,2.5,4.5\end{array}$ \\
\hline $17-22$ & 8.51 & $\begin{array}{c}-4.5,-2.5,-0.5 \\
0.5,2.5,4.5\end{array}$ \\
\hline $23-28$ & 15.16 & $\begin{array}{c}-4.5,-2.5,-0.5 \\
0.5,2.5,4.5\end{array}$ \\
\hline
\end{tabular}

\subsection{Grid analysis}

The grid size is one of the important parameters in numerical modeling. Generally speaking, the smaller the grid is, the higher the numerical calculation accuracy is. While the grid is too small, the calculation time is too long. FDS user's guide has suggested that when $4 \leq \frac{D^{*}}{\delta} \leq 16$, the calculation is more reasonable.

$$
D^{*}=\left(\frac{Q}{\rho_{0} C_{p} T_{0} \sqrt{g}}\right)^{\frac{2}{5}}
$$

Where, $Q$ is the heat release rate of the fire source, $\mathrm{KW}$; $\rho_{0}$ is the tunnel air density, $\mathrm{kg} / \mathrm{m}^{3} ; C_{p}$ is the specific heat capacity of the air at constant pressure, $\mathrm{kJ} / \mathrm{kg} ; g$ is the acceleration of gravity, $\mathrm{m} / \mathrm{s}^{2} ; \delta$ is the grid size.

When the ambient temperature is $20^{\circ} \mathrm{C}$, for $\mathrm{HRR}=3.57 \mathrm{KW}, D^{*}$ obtained according to the equation 2 
is $0.098 \mathrm{~m}$, and it is calculated that $0.006 \mathrm{~m} \leqslant \delta \leqslant 0.0245 \mathrm{~m}$ for numerical simulation. Before the actual simulation, three grid sizes were used for comparison to test the independence of the grid. Figure 2 shows the ceiling's temperature rise at upstream of the fire source in the tunnel with different grid sizes. It can be seen from the figure that the temperature of the tunnel with a grid size of $0.01 \mathrm{~m}$ and $0.02 \mathrm{~m}$ are close near the fire source, while the temperature of the $0.025 \mathrm{~m}$ grid is slightly lower. The three grid sizes have no difference in temperature far from the fire source. Obviously, when the grid size is reduced to less than $0.02 \mathrm{~m}$, the calculation results are not significantly improved. But the calculation time is doubled. Therefore, $0.02 \mathrm{~m}$ is selected to simulate.

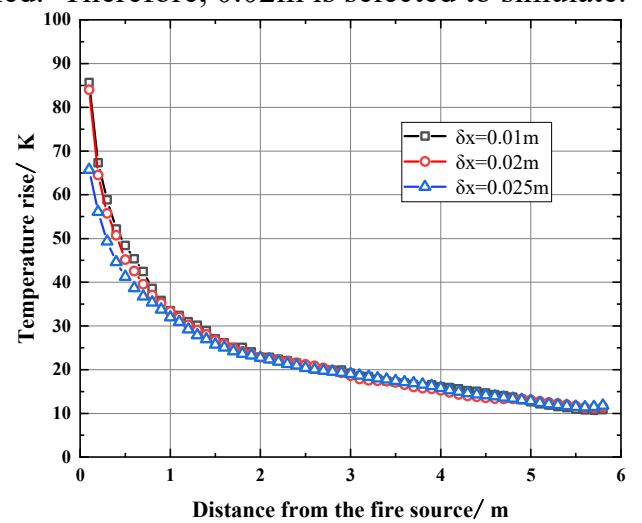

Fig. 2. Temperature rise of the ceiling upstream of the fire source in the tunnel with different grid sizes

\section{Results and Analysis}

\subsection{Smoke exhaust efficiency}

The chimney effect is the main driving force for smoke exhaust from the shaft. It is caused by the density difference between the surrounding fresh air and the hot smoke in the shaft. And the density difference is caused by the temperature difference, which causes buoyancy to drive the smoke to move vertically in the shaft.

Figure $3 \mathrm{a}$ and Figure $3 \mathrm{~b}$ respectively show the smoke exhaust state in the stable phase when the shaft is located downstream of the fire source and upstream of the fire source. The smoke exhaust efficiency is defined as $\zeta$ :

$$
\zeta=\frac{\dot{Q}_{s}}{\dot{Q}_{t}}=\frac{C_{p} \dot{m}_{s} \Delta T_{s}}{C_{p} \dot{m}_{t} \Delta T_{t}}=\frac{C_{p} v_{s} A_{s} \rho_{s} \Delta T_{s}}{C_{p} v_{t} H_{t} W_{t} \rho_{t} \Delta T_{t}}
$$

Where, $\dot{Q}_{s}$ is the heat released through the shaft, $\mathrm{kW}$; $\dot{Q}_{t}$ is the heat near the bottom of the shaft, $\mathrm{kW} ; C_{p}$ is the specific heat capacity of air, $\mathrm{kJ} / \mathrm{kg}$ (it does not change

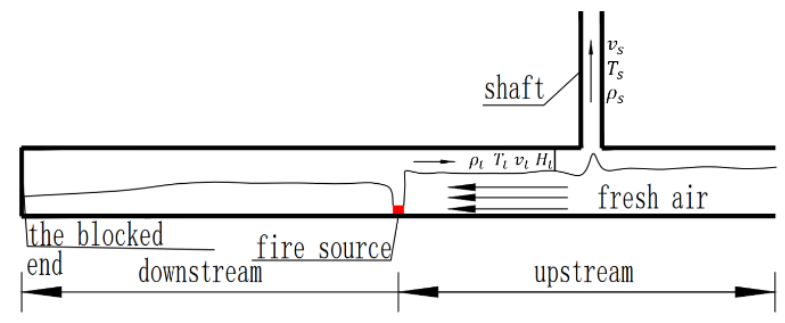

Fig.3a. Schematic diagram of smoke exhaust in the model tunnel $\left(D_{s}<0\right)$

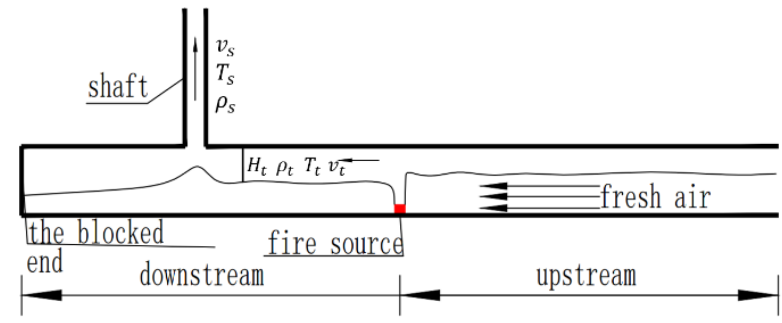

Fig.3b. Schematic diagram of smoke exhaust in the model tunnel $\left(D_{s}>0\right)$

much with temperature, and is regarded as a fixed value here); $\dot{m}_{s}$ is the mass flow rate discharged through the shaft, $\mathrm{kg} / \mathrm{s} ; \Delta T_{s}$ is the temperature rise in the shaft, $\mathrm{K} ; \dot{m}_{t}$ is the mass flow rate of the flue gas at the bottom of the shaft, $\mathrm{kg} / \mathrm{s} ; \Delta T_{t}$ is the temperature rise of the smoke layer, $\mathrm{K} ; \rho_{s}$ is the smoke density in the shaft, $\mathrm{kg} / \mathrm{m}^{3} ; v_{s}$ represents the exhaust velocity through the shaft, $\mathrm{m} / \mathrm{s} ; A_{s}$ is the cross-sectional area of the shaft, $\mathrm{m}^{2} ; \rho_{t}$ is the smoke layer density, $\mathrm{kg} / \mathrm{m}^{3} ; v_{t}$ is the smoke layer propagation velocity, $\mathrm{m} / \mathrm{s} ; H_{t}$ is the thickness of the smoke layer near the upper reaches of the shaft bottom, $\mathrm{m} ; W_{t}$ is the tunnel width, m; where $v_{s}$ and $v_{t}$ are measured and calculated by the FDS flow measuring device, $H_{t}$ is measured by the FDS smoke measuring device, $T_{s}$ is represented by the average temperature in the shaft, and $T_{t}$ is represented by the average temperature of the smoke layer at the bottom of the shaft.

According to the ideal gas state equation:

$$
\rho_{a} T_{a}=\rho_{s} T_{s}=\rho_{t} T_{t}
$$

Substituting formula (4) into formula (3), we get:

$$
\zeta=\frac{v_{s} A_{s} T_{t} \Delta T_{S}}{v_{t} H_{t} W_{t} T_{s} \Delta T_{t}}
$$

This paper calculates the smoke exhaust efficiency $\zeta$ for each case with the shaft, as shown in Figure 4. When $D_{s}<0$ and $\left|D_{s}\right|$ gradually increases (when the shaft is between the fire source and the blocked end, and is far from the fire source), the smoke exhaust efficiency of the shaft will first decrease and then stabilize. This is because when the shaft is closer to the fire source, the amount of smoke discharged per unit time is larger, and the temperature of the discharged smoke is high, so the smoke exhaust efficiency is higher. As the fire develops, smoke will gradually accumulate at the blocked end, and the vertical shaft of this size has a limited amount of smoke (we will continue to study other vertical shafts later). Therefore, when the shaft is close to the blocked end, the smoke exhaust efficiency will stabilize at a certain value. When $D_{s}>0$ and $\left|D_{s}\right|$ gradually increases (when the shaft is between the fire source and the open end, and is far from the fire source), the smoke exhaust efficiency of the shaft will increase slightly, but the overall value is too small (near 0.1). Because when the shaft is located between the fire source and the open end, the smoke will continue to be discharged from the open end of the tunnel. The smoke volume is large and will not accumulate, and the shaft at this height has plug phenomenon. Fresh air is mixed with the smoke, so the exhaust efficiency is low. The closer the shaft is to the open end (when $\left|D_{s}\right|$ increases), the less obvious the plug phenomenon is, and the exhaust efficiency will slightly increase. In addition, for a tunnel 
with a fixed $D_{s}, \zeta$ decreases with the increase of the heat release rate of the fire source. When the heat release rate of the fire source increases, the smoke volume of the tunnel fire increases. At the same time, the smoke exhaust volume of the shaft doesn't increase a lot, so $\zeta$ will decrease slightly.

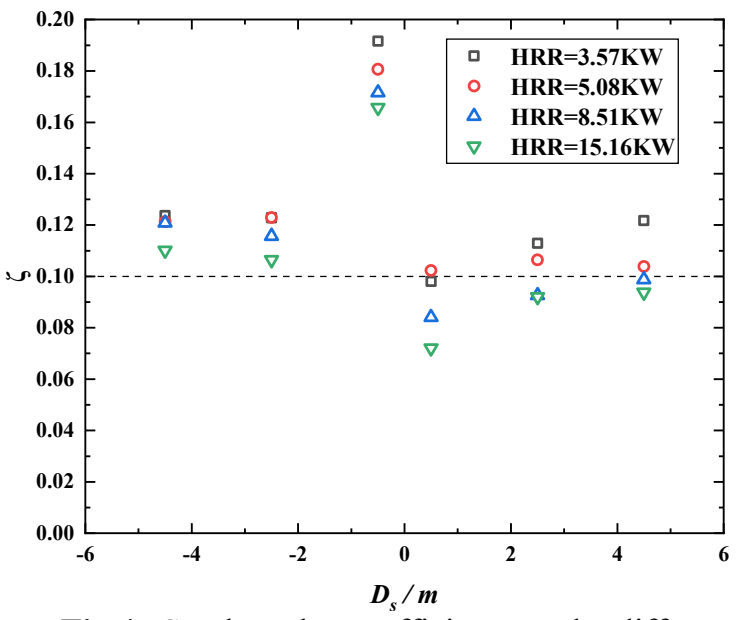

Fig.4. Smoke exhaust efficiency under different cases

Figure 5 shows the temperature distribution at different heights in the shaft under various working conditions. It can be seen from the figure that as $\left|D_{s}\right|$ increases (the distance between the shaft and the fire source increases), the temperature in the shaft will decrease. Among all the shaft positions, the temperature at $D_{s}=-0.5 \mathrm{~m}$ is the highest, and the temperature at $D_{s}=-$ $4.5 \mathrm{~m}$ is the lowest, which also proves that the temperature attenuation of the blocked end of the tunnel is more severe than that of the open end. It is worth noting that $\mathrm{Ji}^{[10]}$ previously found that when the heat release rate of the fire source was small on the small-scale experimental platform of 1:6, the plug phenomenon began to occur at the height of the $0.4 \mathrm{~m}$ shaft. The model scale in this paper is $1: 10$, the height of the shaft is $1 \mathrm{~m}$. And in Figure 5, under many conditions (especially when $D_{s}=-0.5 \mathrm{~m}$ and $D_{s}=0.5 \mathrm{~m}$ ), the temperature distribution in the shaft increases and then decreases with the increasing height of the measuring point in the shaft. Because in these cases, the smoke discharged from the bottom of the shaft mixes with fresh air, and the plug phenomenon occurs. As the distance between the shaft and the fire source increases, the plug phenomenon weakens.

\subsection{Temperature distribution of the ceiling}

Figures $6 \mathrm{a}$ and $6 \mathrm{~b}$ respectively show the average temperature distribution of the model tunnel's ceiling.

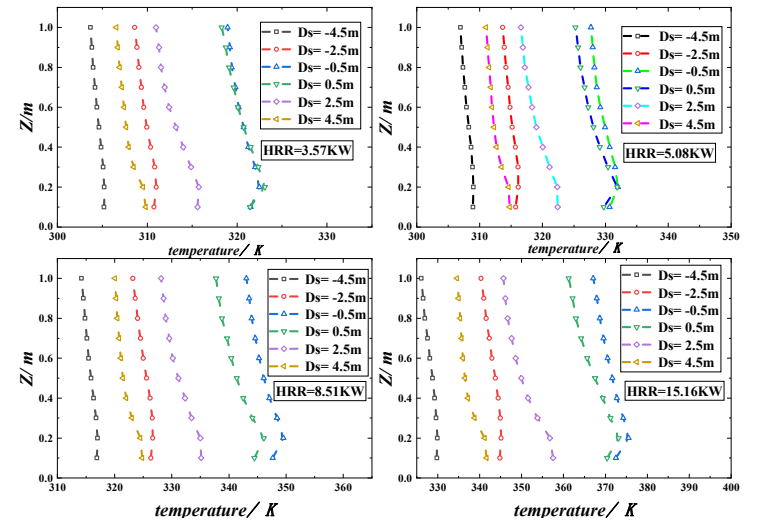

Fig. 5. Temperature distribution in shaft under different cases

Wherever the shaft is located downstream or upstream of the fire source $(\mathrm{HRR}=15.16 \mathrm{KW})$. The ceiling's highest temperature position is at $X=5.4 \mathrm{~m}$, which proves that in all cases, the flame tilted towards the blocking end. Among them, the square group is the control group without shaft. It can be seen from the figure that when the shaft is located downstream of the fire source, compared with the situation without shaft, the ceiling's temperature at the downstream of the fire source attenuates more and the maximum temperature of the ceiling decreases to a certain extent, which also confirms the smoke exhaust effect of the shaft. When the shaft is located upstream of the fire source, the temperature of the ceiling at the upstream of the fire source attenuates intensified. However, when $D_{s}=0.5 \mathrm{~m}$, its maximum temperature exceeds the control group without shaft. A similar rule also appears in the case of other fire source heat release rates. When $D_{s}>0$ and the shaft is very close to the fire source, the smoke in the shaft is quickly discharged, and fresh air at the open end is continuously supplied, which will intensify the combustion of the fire source, making the highest temperature of the ceiling bigger than other cases.

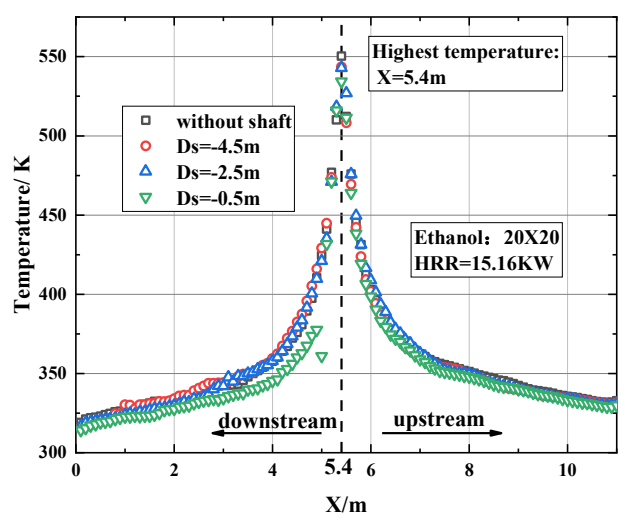

Fig. 6a. Ceiling's temperature distribution when the shaft is located at downstream of the fire source $(\mathrm{HRR}=15.16 \mathrm{KW})$ 


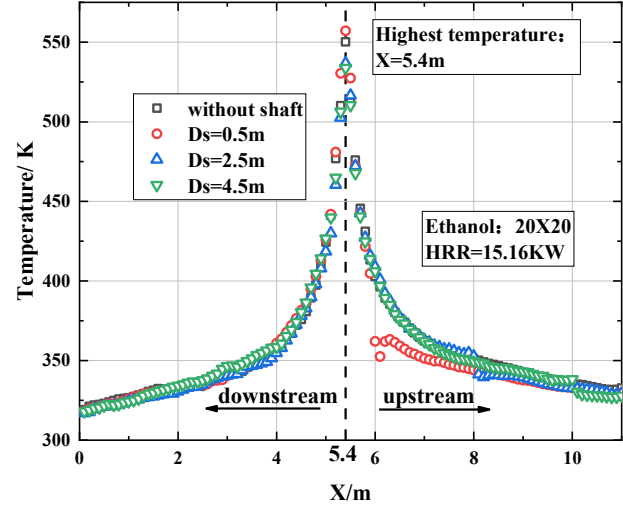

Fig. 6b. Ceiling's temperature distribution when the shaft is located at upstream of the fire source $(\mathrm{HRR}=15.16 \mathrm{KW})$

Based on the theoretical derivation and experimental verification in the previous research ${ }^{[17]}$, the attenuation law of the tunnel ceiling's temperature conforms to double exponential attenuation, namely:

$$
\frac{\Delta T_{x}}{T_{a}}=A_{1} \cdot \exp \left[-\alpha_{1}\left(\frac{x}{H}\right)\right]+A_{2} \cdot \exp \left[-\alpha_{2}\left(\frac{x}{H}\right)\right]
$$

Where $\mathrm{x}$ is the distance between the upstream measurement point and the fire source, and $\Delta T_{x}$ is the average temperature rise of the measurement point relative to the ambient temperature, and $T_{a}$ is the ambient temperature. Among them, $A_{1}, A_{2}, \alpha_{1}$ and $\alpha_{2}$ are fitting coefficients. As shown in Figure 7, the attenuation law of tunnel ceiling temperature under different fire source heat release rates is very different. And the greater the heat release rate is, the more severe the ceiling temperature attenuation is, which conforms to the double exponential decay law. Figure 6a shows that when the shaft is located downstream of the fire source $\left(D_{s}<0\right)$, the temperature attenuation of the ceiling at the upstream of the fire source at each shaft location is similar. Therefore, we fitted the ceiling temperature upstream of the fire source for the cases of $D_{s}<0$, as shown in Figure 8. However, when the shaft is located upstream of the fire source $\left(D_{s}>0\right)$, the temperature of the smoke will drop rapidly after passing through the shaft, and the temperature distribution upstream of the fire source no longer meets the same rule.

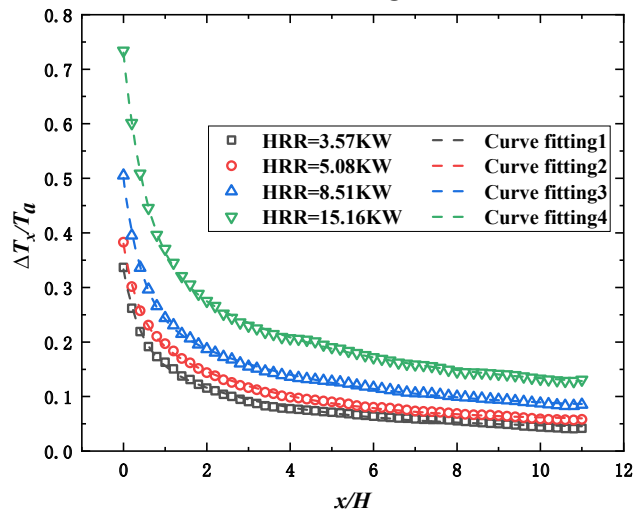

Fig. 7. Dimensionless temperature rise diagram of different HRR $\left(D_{s}=-4.5 \mathrm{~m}\right)$
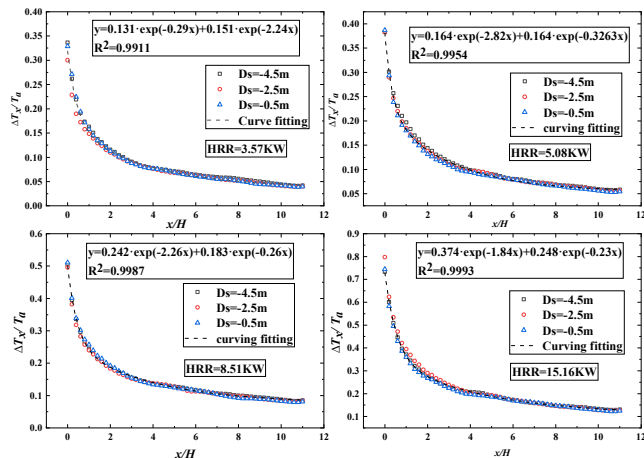

Fig. 8. Fitting diagram of dimensionless temperature rise at upstream of fire source $\left(D_{s}<0\right)$

\section{Conclusion}

A 1:10 small-scale model was established through FDS, and the influence of the fire source heat release rate and the position of the shaft on the tunnel ceiling's temperature distribution and smoke exhaust efficiency in the blocked tunnel at one end was studied. The conclusions are as follows:

(1) When one end of the tunnel is blocked, the flame will tilt towards the blocked end during the fire stabilization stage. No matter where the shaft is, the flame will still tilt towards the blocked end.

(2) When the shaft is located downstream of the fire source, as the shaft is far away from the fire source, the smoke exhaust efficiency first decreases and then stabilizes at a certain value. When the shaft is located upstream of the fire source, as the shaft moves away from the fire source, the smoke exhaust efficiency slight increase, the overall is relatively small (about 0.1). The shaft located downstream of the fire source has a higher smoke exhaust efficiency than the shaft located upstream of the fire source. In the numerical simulation, the vertical shaft has plug phenomenon, and it will gradually weaken as the distance between the shaft and the fire source increases.

(3) The installation of the shaft will increase the temperature attenuation in the tunnel and discharge more smoke. When the shaft is located downstream of the fire source, the ceiling temperature decay upstream of the fire source is only related to the heat release rate of the fire source, and has nothing to do with the specific shaft location.

\section{Acknowledgement}

This research was financially supported by Graduate Scientific Research and Innovation Foundation of Chongqing, China (Grant No. CYS19009).

\section{References}

1. M. C. Weng, X. L. Lu, F. Liu, C. X. Du, Applied Thermal Engineering, 94 , 422 (2016)

2. L. X. Yu, F. Liu, Y. Q. Liu, M. C. Weng, Tunnelling and Underground Space Technology, 71 ,81(2018) 
3. B. Lou, Y. Qiu, X. Long, Journal of Applied Fluid Mechanics, 10(4),1139(2017)

4. K. Ahmed, Z. Y. Yuan, B. Lei, Fire Safety Journal, 62,249 (2013)

5. Z. S. Xu, Q. L. Liu, L. He, H. W. Tao, J. M. Zhao, H. G. Chen, L. J. Li, C. G. Fan, Fire and Materials, 43(7),857 (2019)

6. C. G. Fan, J. Chen, Y. Zhou, X. P. Liu, Fire and Materials, 42(8),974 (2018)

7. Takeuchi, Shoto, T. Aoki, F. Tanaka, K. A. M. Moinuddin, Fire Safety Journal, 91,312 (2017)

8. Q. H. Guo, H. H. Zhu, Y. Zhang, Z. G. Yan, Tunnelling and Underground Space Technology, 99,(2020)

9. B. C. Xie, Y. X. Han, H. Huang, L. N. Chen, Y. Zhou, C. G. Fan, X. P. Liu, Sustainable Cities and Society, $42,521(2018)$

10. J. Ji, Z. H. Gao, C. G. Fan, W. Zhong, J. H. Sun, International Journal of Heat and Mass Transfer, 55(21-22),6032 (2012)

11. Y. F. Wang, X. F. Sun, B. Li, T. Qin, S. Liu, Y. Liu, Applied Thermal Engineering, 114,537 (2017)

12. Z. Y. Yuan, B. Lei, A. Kashef, Fire Technology, 51(3),691 (2015)

13. L. He, Z. S. Xu, F. Markert, J. M. Zhao, Q. L. Liu, H. W. Tao, Z. H. Wang, C. G. Fan, Journal of Wind Engineering and Industrial Aerodynamics, 201(2020)

14. H. Y. Cong, X. S. Wang, P. Zhu, T. H. Jiang, X. J. Shi, Applied Thermal Engineering, 118,127 (2017)

15. J. Ji, C. G. Fan, Z. H. Gao, J. H. Sun. Journal of Civil Engineering and Management, 20(4),466 (2014)

16. J. Wang, Z. K. Wu, X. Xiao,Y. P. He, (2006)

17. L. Gong, L. Jiang, S. Y. Li, N. Shen, Y. C. Zhang, J. H. Sun, International Journal of Thermal Sciences, 102,319 (2016) 